\title{
Report of the Korean Association of External Quality Assessment Service on Complement and Immunoglobulin (2018)
}

Kyeong-Hee Kim

Department of Laboratory

Medicine, Dong-A

University College of

Medicine, Busan, Korea

Corresponding author: Kyeong-Hee Kim

Department of Laboratory

Medicine, Dong-A University

Hospital, Dong-A University

College of Medicine, 26

Daesingongwon-ro, Seo-gu,

Busan 49201, Korea

Tel: +82-51-240-2850

Fax: +82-51-255-9366

E-mail: progreen@dau.ac.kr

pISSN: 2384-2458

elSSN: 2288-7261
In 2018, the complement and immunoglobulin proficiency testing program of the Korean Association of External Quality Assessment Service included complement, free light chain, immunoglobulin, and anti-cyclic citrullinated peptide (anti-CCP). Tests on all nine items were conducted. The specimen used in the complement and immunoglobulin proficiency testing program was Liquichek Immunology Control from Bio-Rad (Bio-Rad Laboratories, USA). In April and October, three quality control specimens were frozen and delivered. The quantitative proficiency testing report included the number of participating organizations in each group, mean, standard deviation, coefficient of variation (CV), median, minimum, and maximum values. The number of organizations participating in each test varied and ranged from 29 free light chains to 115 anti-CCP participants. The median CV of C3 was $4.9 \%$, and the median CV of C4 was $8.45 \%$, which was statistically significantly lower $(P=0.013)$. The median CV for the free light chain $\kappa$ and the free light chain $\lambda$ were 7.96 and 6.21, respectively, with a high $\mathrm{CV}$ for the free light chain $\kappa$, but no statistical difference $(P=0.092)$. The median CV of immunoglobulin A (IgA), immunoglobulin G (IgG), and immunoglobulin $\mathrm{M}(\operatorname{IgM})$ were good at $4.5,4.48$, and 3.56, but the median $\mathrm{CV}$ of immunoglobulin $\mathrm{E}$ was 7.75 , which was statistically significantly higher than that of $\operatorname{IgA}$, IgG, and IgM $(P=0.0014)$. The anti-CCP, which evaluated the qualitative results, was correct 99.1-100\% of the time, with the exception being for the IG-18-02 specimen. The anti-CCP, which lacks international standards, requires patient-derived proficiency testing materials. (Lab Med Qual Assur 2019;41:195-200)

Key Words: Korean Association of External Quality Assessment Service, Complement, Immunoglobulins, Free light chain, Anti-cyclic citrullinated peptide

\section{서론}

외부정도관리프로그램에 참여하는 것은 검사의 신뢰도를 향 상시킬 수 있는 중요한 방법이다. 대한임상검사정도관리협회 에서는 2016년부터 새로운 운영방식의 차세대 신빙도조사사 업을 시행하고 있다. 2018년에는 총 6개의 대분류가 있으며, 진단면역학 대분류 아래에는 6 개의 중분류로 구성되며 또 14 개의 세부프로그램으로 나뉜다. 진단면역학 세부프로그램의 하나인 보체 · 면역글로불린검사는 총 9가지 검사의 신빙도 조사 항목을 가지고 있다. 보체와 유리경쇄, 면역글로불린 및 항-cyclic citrullinated peptide (anti-CCP)가 포함되며 이들
검사들은 각각 전신성 홍반성 루푸스[1], 다발성 골수종[2], 자가면역성 간염[3], 류마티스관절염[4]의 진단기준에 포함되 어 임상적으로 중요하다.

이에 저자는 2018년 대한임상검사정도관리협회의 신빙도조 사사업으로 실시되었던 보체 · 면역글로불린검사 프로그램에 대한 신빙도조사사업 결과를 분석하여 보고하고자 한다.

\section{재료 및 방법}

\section{1. 조사항목}

조사항목은 complement C3, complement C4, free light 


\section{LABORATORY MEDICINE and QUALITY ASSURANCE}

Kyeong-Hee Kim • External Quality Assessment of Complement and Immunoglobulin

chain $\kappa$, free light chain $\lambda$, immunoglobulin A (IgA), immunoglobulin G (IgG), immunoglobulin M (IgM), immunoglobulin E (IgE), 항-CCP검사의 9가지 항목에 대한 신 빙도조사를 실시하였다.

\section{2. 외부신빙도조사 물질}

보체·면역글로불린검사 프로그램의 외부신빙도조사에 이
용된 물질은 액상으로 된 정도관리물질이었다. Bio-Rad사 (Bio-Rad Laboratories, Hercules, CA, USA)의 Liquichek Immunology Control을 사용하였다. 4월과 10월 연 2회에 걸 쳐 회차별로 3 개의 정도관리물질이 냉동보관되어 배송되었으 며, 냉동검체 수령 후 가능한 빠른 시간 내에 검사를 시행하 도록 안내하였다. 냉동검체를 실온 $\left(18^{\circ} \mathrm{C}\right.$ 에서 $\left.25^{\circ} \mathrm{C}\right)$ 에서 1 시 간 가량 방치하여 해동하고, 맑은 혈청이 아닌 경우 원심한 후

Table 1. Distribution of the complement and free light chain results in 2018

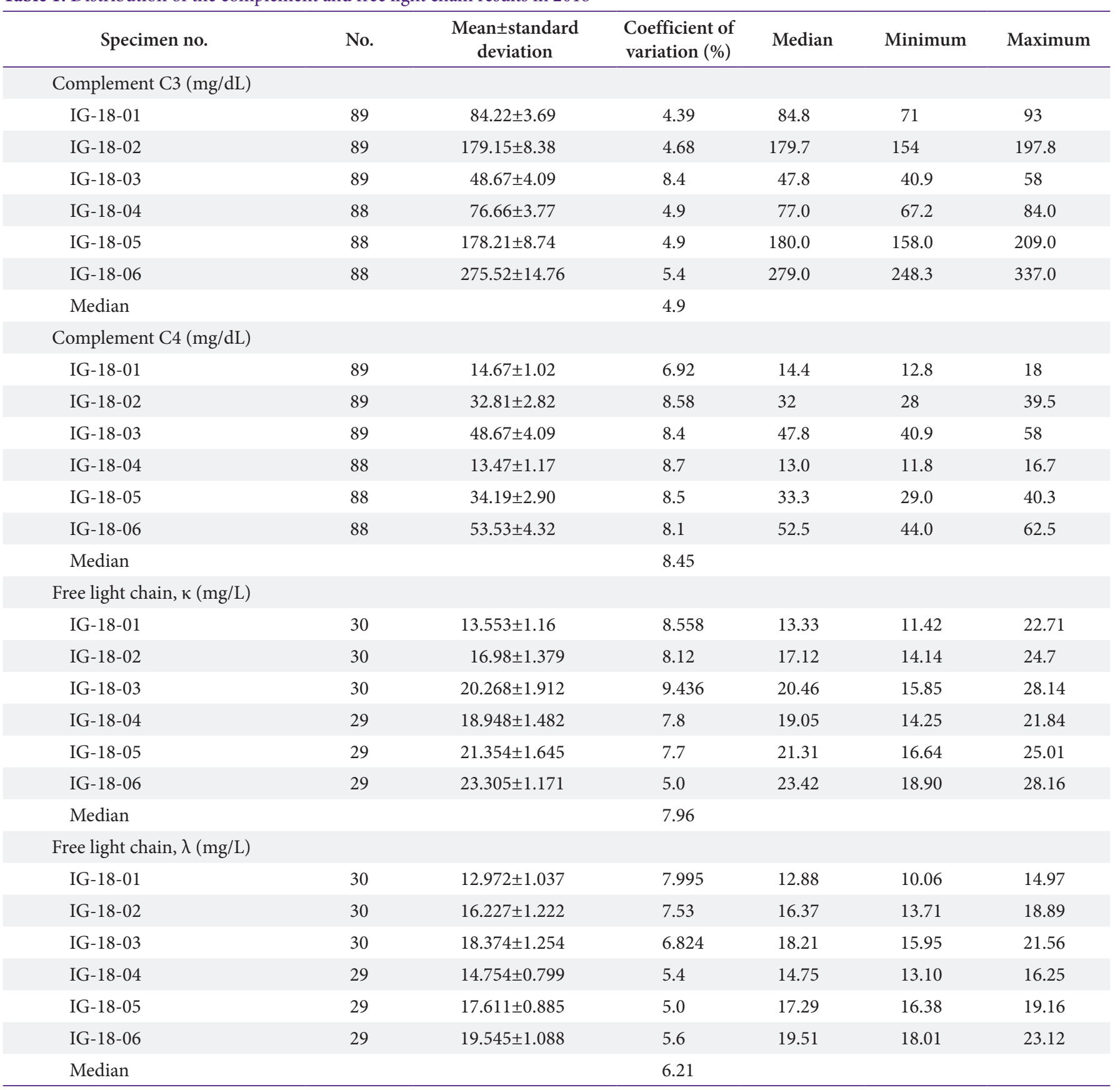




\section{LABORATORY MEDICINE and QUALITY ASSURANCE}

Kyeong-Hee Kim • External Quality Assessment of Complement and Immunoglobulin

에 맑은 혈청을 사용하도록 하였다. 검사 시행 후 회신 마감 일 내에 대한임상검사정도관리협회 신빙도조사사업 홈페이지 (http://eqas.keqas.org)에 결과를 입력하도록 안내하였다.

\section{3. 결과 판정 및 분석}

보체·면역글로불린검사 프로그램의 각각 검사에 대해 서 기관에서 입력한 각 검사항목에 대한 정보와 결과를 기
반으로 기기회사, 기기에 따라 통계분석을 시행하였고, 이 를 전체 참여기관의 분포를 보여주는 공통보고서와 개별기관 의 평가결과를 보여주는 기관별 보고서로 나누어 보고하였 다. Complement C3, complement C4, free light chain $\kappa$, free light chain $\lambda$, $\operatorname{IgA}, \operatorname{IgG}, \operatorname{IgM}, \operatorname{IgE}$ 검사는 정량적 결과를, 항-CCP검사는 정성적 결과를 분석하였다. 공통보고서는 3단 계로 그룹화하여 통계치를 제시하였다. 전체 참여기관에 해당

Table 2. Distribution of the immunoglobulin results in 2018

\begin{tabular}{|c|c|c|c|c|c|c|}
\hline Specimen no. & No. & $\begin{array}{c}\text { Mean } \pm \text { standard } \\
\text { deviation }\end{array}$ & $\begin{array}{l}\text { Coefficient of } \\
\text { variation }(\%)\end{array}$ & Median & Minimum & Maximum \\
\hline \multicolumn{7}{|c|}{ Immunoglobulin A (mg/dL) } \\
\hline IG-18-01 & 80 & $112.09 \pm 4.88$ & 4.36 & 112.8 & 102 & 121 \\
\hline IG-18-02 & 80 & $232.2 \pm 10.76$ & 4.64 & 229.6 & 215.8 & 264 \\
\hline IG-18-03 & 80 & $340.06 \pm 17.79$ & 5.23 & 337 & 312.1 & 395 \\
\hline IG-18-04 & 80 & $112.88 \pm 5.84$ & 5.2 & 113.1 & 98.0 & 124.0 \\
\hline IG-18-05 & 80 & $239.38 \pm 8.21$ & 3.4 & 240.0 & 221.0 & 292.0 \\
\hline IG-18-06 & 80 & $358.43 \pm 12.73$ & 3.6 & 361.3 & 332.6 & 457.5 \\
\hline Median & & & 4.5 & & & \\
\hline \multicolumn{7}{|c|}{ Immunoglobulin G (mg/dL) } \\
\hline IG-18-01 & 77 & $740.37 \pm 36.84$ & 4.98 & 735 & 634 & 837 \\
\hline IG-18-02 & 77 & $1,261.29 \pm 49.75$ & 3.94 & $1,264.2$ & $1,155.4$ & 1,570 \\
\hline IG-18-03 & 77 & $1,725.11 \pm 75.22$ & 4.36 & 1,710 & 1,579 & 1,910 \\
\hline IG-18-04 & 77 & $810.15 \pm 36.91$ & 4.6 & 807.6 & 735.0 & 931.0 \\
\hline IG-18-05 & 77 & $1,371.65 \pm 54.77$ & 4.0 & $1,383.0$ & $1,262.0$ & $1,570.0$ \\
\hline IG-18-06 & 77 & $1,912.82 \pm 94.46$ & 4.9 & $1,919.0$ & $1,751.0$ & $2,190.0$ \\
\hline Median & & & 4.48 & & & \\
\hline \multicolumn{7}{|c|}{ Immunoglobulin $\mathrm{M}$ (mg/dL) } \\
\hline IG-18-01 & 77 & $49.3452 \pm 3.1535$ & 6.3907 & 49 & 42 & 57 \\
\hline IG-18-02 & 77 & $108.7716 \pm 3.5654$ & 3.2778 & 110 & 102 & 129 \\
\hline IG-18-03 & 77 & $159.409 \pm 5.4779$ & 3.4364 & 160.6 & 147.7 & 201 \\
\hline IG-18-04 & 77 & $51.24 \pm 2.56$ & 5.0 & 51.0 & 45.0 & 60.0 \\
\hline IG-18-05 & 77 & $120.53 \pm 4.43$ & 3.7 & 120.9 & 109.0 & 144.0 \\
\hline IG-18-06 & 77 & $180.55 \pm 4.92$ & 2.7 & 181.0 & 167.0 & 233.0 \\
\hline Median & & & 3.56 & & & \\
\hline \multicolumn{7}{|c|}{ Immunoglobulin E (IU/mL) } \\
\hline IG-18-01 & 76 & $73.39 \pm 5.76$ & 7.85 & 73.7 & 50.1 & 87.7 \\
\hline IG-18-02 & 76 & $156.02 \pm 11.79$ & 7.56 & 156.9 & 114 & 185.3 \\
\hline IG-18-03 & 76 & $228.17 \pm 20.62$ & 9.04 & 231.6 & 163 & 270.8 \\
\hline IG-18-04 & 76 & $44.41 \pm 3.47$ & 7.8 & 44.3 & 35.8 & 62.0 \\
\hline IG-18-05 & 76 & $127.77 \pm 9.69$ & 7.6 & 127.3 & 96.7 & 146.6 \\
\hline IG-18-06 & 76 & $204.64 \pm 15.67$ & 7.7 & 203.7 & 168.8 & 237.0 \\
\hline Median & & & 7.75 & & & \\
\hline
\end{tabular}




\section{LABORATORY MEDICINE and QUALITY ASSURANCE}

\section{Kyeong-Hee Kim • External Quality Assessment of Complement and Immunoglobulin}

하는 통계, 기기회사를 기준분류로 한 그룹의 통계와 각 기기 를 세분류한 그룹의 통계를 각각 제시하였다.

정량검사 공통보고서에는 각 그룹별 참여기관 수, 평균, 표준편차, 변동계수, 중앙값, 최소값과 최대값이 포함되도 록 하였다. 평균, 표준편차, 변동계수의 경우 해당 분류별 분 석에서 이상치를 제거한 후 분석한 값을 제시하였다. 이상치 는 75퍼센타일 값(Q3)과 25퍼센타일 값(Q1)의 차(Q3-Q1, interquartile range [IQR])의 1.5배를 초과하여 Q1보다 낮 거나 Q3보다 높은 결과값 $(<\mathrm{Q} 1-1.5 \times \mathrm{IQR}$ 또는 $>\mathrm{Q} 3+1.5$ $\times \mathrm{IQR})$ 으로 정의하였다. 해당 분류에 속하는 기관 수가 10 개 미만인 경우에는 평균, 표준편차, 변동계수, 표준편차지수 (standard deviation index, SDI)를 제시하지 않고, 기관 수 가 3 개 미만인 경우에는 중앙값도 제시하지 않으며, 기관 수 가 1 개인 경우에는 중앙값만 보고하였다. 정량검사 기관별 보 고서에는 전체기관 및 기준분류의 히스토그램과 최대 12 개까 지 누적된 SDI를 표시하는 레비-제닝스 차트 및 각 기관의 결 과에 대해 기준분류 및 세분류로 $\mathrm{SDI}$ 를 제공하였다. 항-CCP 정성검사 공통보고서에는 기관에서 보고한 검사결과들이 기 준분류 및 세분류별 통계로 구성되었다. 정성검사 기관별 보고 서에는 검사결과, intended response 및 평가결과가 있으며, intended response는 신뢰할 만한 정답이 없는 경우에는 결과 를 보고한 기관에서 $80 \%$ 이상의 일치를 보이는 결과로 하였 다.

통계적 분석을 위해서 통계프로그램은 MedCalc Software

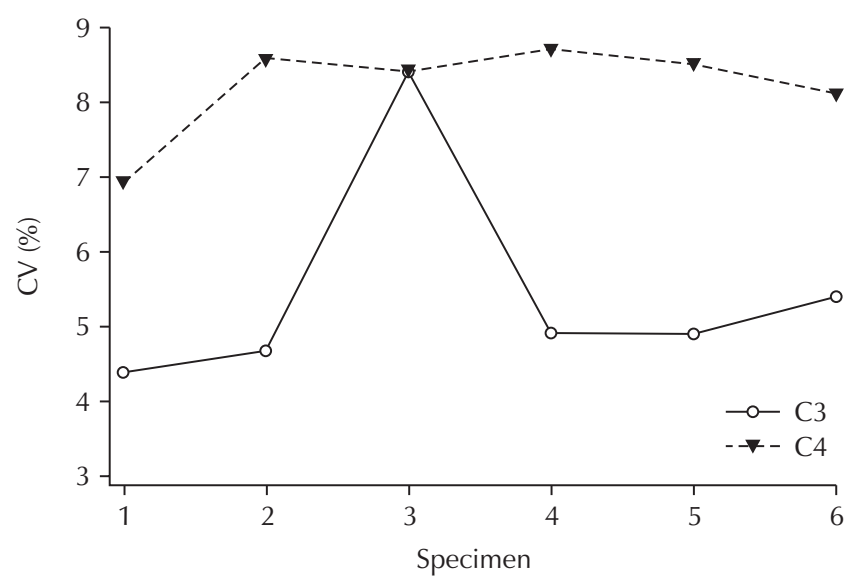

Fig. 1. Plot of the $\mathrm{CV}$ for complement $\mathrm{C} 3$ and complement $\mathrm{C} 4$ in 2018. The $\mathrm{X}$-axis is the specimen number, which is displayed sequentially from IG-18-01 to IG-18-06. The difference of immunoglobulin G CV was statistically significant between $\mathrm{C} 3$ and $\mathrm{C} 4$ using the Mann-Whitney test $(P=0.013)$ for the analyses. Abbreviation: $\mathrm{CV}$, coefficient of variation. ver. 16.8 (MedCalc Software, Mariakerke, Belgium)을 사 용하였다. 면역글로불린 간의 변동계수 차이 유무는 Friedman test를 이용하였고, complement C3와 complement C4 그리고 free light chain $\kappa$ 와 free light chain $\lambda$ 사이의 변동계 수 차이는 Mann-Whitney test를 통해 구하였다. P값이 0.05 이하인 경우 통계적으로 유의하다고 간주하였다.

\section{결과 및 고찰}

2018년 보체 · 면역글로불린검사 프로그램 신빙도조사는 각 검사마다 참여하는 기관의 수가 달랐으며, free light chain의 참여기관 29 개에서 항-CCP 참여기관 115 개로 다양하였다. 각 정량적 검사항목별로 참여기관 수, 평균, 표준편차, 변동계수, 중앙값, 최소값과 최대값의 분포는 Table 1 과 Table 2 와 같다. 보체의 경우 $\mathrm{C} 3$ 의 변동계수 중앙값은 $4.9 \% \mathrm{C} 4$ 의 변동계수 중 앙값은 8.45\%로 $\mathrm{C} 3$ 의 변동계수가 통계적으로 유의하게 낮았 다 $(P=0.013)$ (Fig. 1). College of American Pathologists에 서 주관하는 신빙도조사사업의 S-C 2016 프로그램에서도 C3 의 변동계수는 $4.1 \%-5.1 \%$ 의 범위를 보였지만 $\mathrm{C} 4$ 의 변동계수 는 6.7\%-9.9\% 범위 내에 있어 국내와 유사하였다. 이는 체내 에서 $\mathrm{C} 3$ 가 더 높은 농도로 존재하기 때문에 낮은 변동계수를 보인 것으로 해석된다.

Free light chain $\kappa$ 와 free light chain $\lambda$ 의 변동계수의 중앙 값은 각각 7.96 과 6.21로 free light chain $\kappa$ 의 변동계수가 높

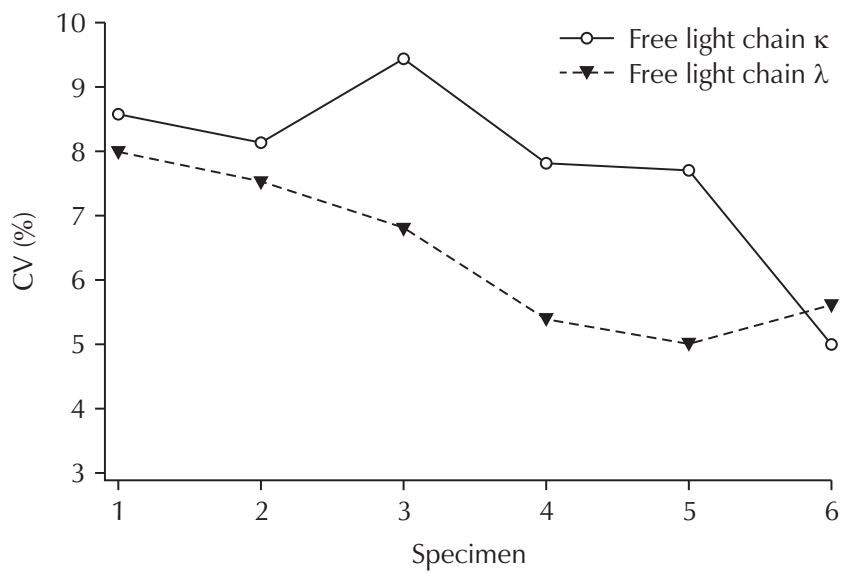

Fig. 2. Plot of the CV for free light chain $\kappa$ and free light chain $\lambda$ in 2018. The $\mathrm{X}$-axis is the specimen number, which is displayed sequentially from IG-18-01 to IG-18-06. The CV was not significantly different between free light chain $\kappa$ and free light chain $\lambda$ using the Mann-Whitney test for the analyses $(P=0.092)$. Abbreviation: $\mathrm{CV}$, coefficient of variation. 


\section{LABORATORY MEDICINE and QUALITY ASSURANCE}

\section{Kyeong-Hee Kim • External Quality Assessment of Complement and Immunoglobulin}

았지만 통계적 차이는 없었다 $(P=0.092)$ (Fig. 2). 단클론감마 병증 및 형질세포 관련 질환의 진단기준에 포함되는 중요한 검 사이지만 국내에서는 29 개 기관에서만 검사가 시행되고 있었 다[2]. 의료기관의 상당수 검사가 수탁 의뢰되고 있을 것으로 추측할 수 있겠다.

면역글로불린은 참여기관이 일정하지 않았는데 IgA가 80개 로 가장 많았으며, $\operatorname{IgG}$ 및 $\mathrm{IgM}$ 77개 기관, $\mathrm{IgE} 76$ 개 기관이었 다. $\mathrm{IgA}, \mathrm{IgG}$, 및 $\operatorname{IgM}$ 의 변동계수는 중앙값이 $4.5,4.48,3.56$ 으로 양호하였지만, $\mathrm{IgE}$ 의 변동계수 중앙값은 7.75 로 $\operatorname{IgA}$, $\operatorname{IgG}, \operatorname{IgM}$ 의 변동계수에 비해 통계적으로 유의하게 높았다 $(P=0.0014)$ (Fig. 3). 이는 IgE가 체내에 소량으로 존재하며,

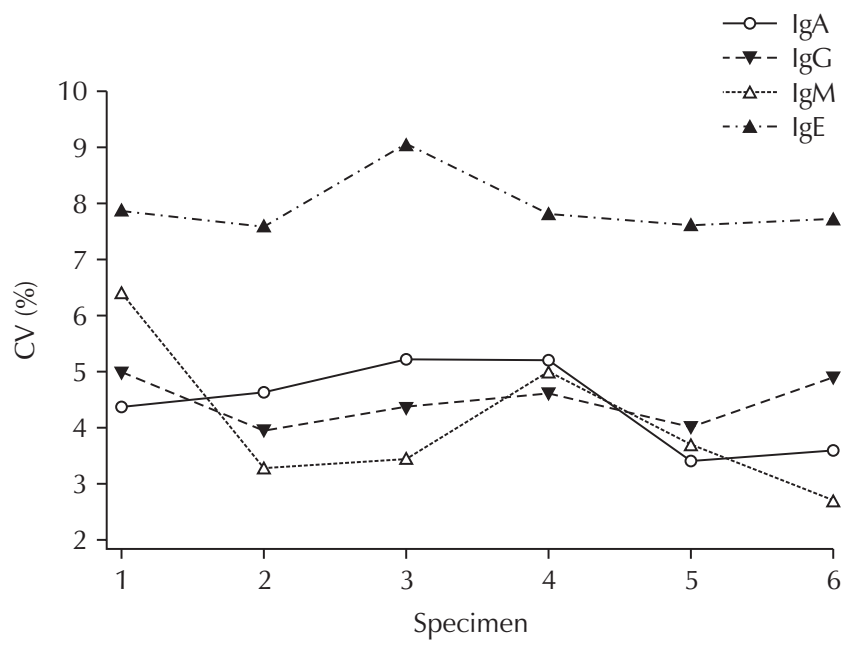

Fig. 3. Plot of the CV for IgA, IgG, IgM, and IgE in 2018. The $\mathrm{X}$-axis is the specimen number, which is displayed sequentially from IG-18-01 to IG-18-06. The CV of IgE was significantly different among immunoglobulin using the Friedman test $(P=0.0014)$ for the analyses. Abbreviations: $\mathrm{CV}$, coefficient of variation; IgA, immunoglobulin A; IgG, immunoglobulin G; IgM, immunoglobulin $\mathrm{M}$; IgE, immunoglobulin $\mathrm{E}$.
측정기기가 BN II system (Siemens Healthcare Diagnostics Ltd., Erlangen, Germany)과 같은 nephelometry부 터 Phadia 100 (Phadia AB, Uppsala, Sweden)과 같은 fluorescent immunoassay까지 다양하기 때문으로 해석된다.

항-CCP는 보체 · 면역글로불린검사 프로그램 중 가장 참여 기관이 많은 검사로, 1 차 108 개 기관 2 차 115 개 기관으로 증 가하였다. 정성적 결과를 평가하였으며 IG-18-02 검체를 제외 하고 99.1\%-100\%의 정답률을 보였다(Table 3). IG-18-02 검 체는 Roche사(Mannheim, Germany)의 시약을 사용하는 검 사실은 모두 음성을 보여 $80 \%$ 일치율에 도달하지 못하였다. 항-CCP 시약은 현재 3세대까지 나와 있으며, Roche사의 시약 설명서에는 상품화된 2세대 검사법에 대해서 표준화하였다고 기술되어 있다. 항-CCP는 현재 국제 표준물질이 없기 때문에 시약 내의 정도관리물질과 calibrator가 임의로 정해진 단위로 써 제공되고 있다. 그래서 서로 다른 시약 간의 정량적 결과는 상호 비교할 수 없으며, 키트 간의 양성 cut-off도 매우 넓은 범 위에 걸쳐 있다. 이러한 문제점들을 해결하기 위해서 2017년 10월에 개최된 세계보건기구(World Health Organization)의 biological standardization 전문가 위원회에서 1차 항-CCP 국제표준물질을 제조하기로 결정하였다[5]. IG-18-02 검체 의 낮은 일치율은 국제표준물질이 없는 상황에서 정도관리물 질을 이용하여 신빙도조사를 하였기 때문에 발생한 문제라고 할 수 있다. 이를 개선하기 위해서는 환자 검체 유래의 신빙도 조사 물질을 제작 개발할 필요성이 있다. 환자 검체 유래 신빙 도조사 물질은 matrix 효과가 없어서 실제 검사실의 정도관리 수행능력을 잘 평가할 수 있을 것으로 생각된다.

2018년 보체 · 면역글로불린검사 프로그램 신빙도조사는 전 반적으로 양호한 변동계수를 보여 주었다. 정성적 평가를 한 항-CCP 항목은 환자 검체 유래 신빙도조사 물질의 필요성을 제기하였다. 본 프로그램의 검사항목들은 다양한 질환의 진단 기준에 포함되어 있기 때문에 지속적인 참여가 필수적이다. 이

Table 3. The proficiency testing results for anti-cyclic citrullinated peptide in 2018

\begin{tabular}{ccccc}
\hline \multirow{2}{*}{ Specimen no. } & No. & \multicolumn{2}{c}{ Result } & Intended \\
\cline { 3 - 4 } & & Negative & Positive & Negative \\
\hline IG-18-01 & 108 & $108(100.0)$ & - & Less than $80 \%$ consensus \\
IG-18-02 & 108 & $43(39.8)^{*}$ & $65(60.2)$ & Positive \\
IG-18-03 & 108 & $1(0.9)$ & $107(99.1)$ & Negative \\
IG-18-04 & 115 & $115(100.0)$ & $114(99.1)$ & Positive \\
IG-18-05 & 115 & $1(0.9)$ & $115(100.0)$ & Positive \\
\hline IG-18-06 & 115 & - & - & \\
\hline
\end{tabular}

Values are presented as a number (\%).

*All 41 laboratories that used reagent of Roche (Mannheim, Germany) reported a negative result. 


\section{LABORATORY MEDICINE and QUALITY ASSURANCE}

Kyeong-Hee Kim • External Quality Assessment of Complement and Immunoglobulin

를 통한 검사실의 질 향상이 환자의 진료영역에 큰 도움이 되 었을 것이다.

\section{REFERENCES}

1. Aringer M, Costenbader K, Daikh D, Brinks R, Mosca M, Ramsey-Goldman R, et al. 2019 European League Against Rheumatism/American College of Rheumatology classification criteria for systemic lupus erythematosus. Arthritis Rheumatol 2019;71:1400-12.

2. Rajkumar SV, Dimopoulos MA, Palumbo A, Blade J, Merlini G, Mateos MV, et al. International Myeloma Working Group updated criteria for the diagnosis of mul- tiple myeloma. Lancet Oncol 2014;15:e538-48.

3. Hennes EM, Zeniya M, Czaja AJ, Pares A, Dalekos GN, Krawitt EL, et al. Simplified criteria for the diagnosis of autoimmune hepatitis. Hepatology 2008;48:169-76.

4. Aletaha D, Neogi T, Silman AJ, Funovits J, Felson DT, Bingham CO 3rd, et al. 2010 Rheumatoid arthritis classification criteria: an American College of Rheumatology/ European League Against Rheumatism collaborative initiative. Arthritis Rheum 2010;62:2569-81.

5. Expert Committee on Biological Standardization, World Health Organization. Requests to initiate new WHO reference material project for blood products and IVDs. Geneva: World Health Organization, 2017. 